
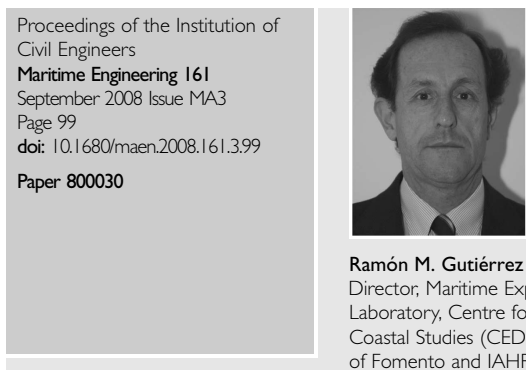

Ramón M. Gutiérrez Serret

Director Maritiene Experinta

Director, Maritime Experimental
Laboratory, Centre for Harbours and

Coastal Studies (CEDEX) Spanish Ministry

of Fomento and IAHR Secretary General

\title{
Editorial: Maritime engineering in Spain
}

\section{R. M. Gutiérrez Serret}

The present issue of Maritime Engineering has been prepared in the context of the collaboration between the Institution of Civil Engineers (ICE) and the International Association of Hydraulic Engineering and Research (IAHR), with the objective of providing a panorama of important activities recently undertaken or currently under way in the maritime field in Spain and especially in its ports, for the purposes of providing information for those involved in other similar projects within a more international framework.

The issue covers design, construction and research and development in a series of coordinated papers presenting some of the most interesting recent maritime engineering projects. The papers-some of which, due to space restrictions, will appear in subsequent issues of Maritime Engineering-have been prepared by engineers from various port authorities belonging to the Spanish port system, as well as from the centre for harbours and coastal studies, part of the Centre of Studies and Experimentation for Public Works (Cedex) of the Ministry of Fomento (Public Works) and consulting and construction firms in the sector.

Notwithstanding the contents of this issue, the intention has been to give a general vision of recent port development under way in the state ports system (28 port authorities which manage 44 ports under the coordination of the public state ports body). Further details of the measures presented as well as the inclusion of other harbours of special interest, both from the state system as well as others from the autonomous regions (ten regions have a coastline responsibility) or indeed belonging to the private sector, go beyond the scope of these papers, and the interested reader wanting further information should contact the author.

An effort has been made with the papers presented to offer a selection of the most important problems encountered-and which continue to be encountered-in Spanish maritime engineering at present and their innovative solutions. In general terms, these problems are caused by the need to locate new port developments in exposed waters, not only because of the general absence of zones with natural protection along the Spanish coastline but also for environmental reasons which lead to great difficulties in locating developments in estuary zones or river mouths, unlike the traditions of the great ports of the world.

This extension of ports with no natural protection is no novelty in the case of Spain; good examples are the ports of Bilbao (1985),
Gijón (1976), Tenerife (1980 and earlier) and various others along the whole length of the peninsula and the Balearic and Canary Islands. What has been and continues to be novel and challenging for Spanish maritime engineers is the sheer scale of these enlargements and their singularity.

In this respect, within the framework of the state port system, the current issue describes important new breakwaters in the ports of Gijón, Ferrol and Coruña in the Atlantic ocean, which extend for $3 \cdot 8,1.0$ and $3 \cdot 4 \mathrm{~km}$, respectively, with maximum heights of 48 , 49 and $64 \mathrm{~m}$ and design wave heights of 9.5, 7.6 and $15 \mathrm{~m}$, respectively, of both rubble-mound and caisson structural types. Further papers to be published in subsequent issues of Maritime Engineering will focus on: the extension of the port of Algeciras Bay with a low-reflecting breakwater in waters 30-40 m deep; the geotechnical problems resulting from the low bearing capacity of the marine bed encountered in the enlargement of the port of Barcelona; environmental aspects of the enlargements at Huelva and Cartagena ports; the unique works carried out for the Americas Cup in the port of Valencia; and significant features of the works undertaken at Villagarcia de Arosa, Alicante and Tarragona.

All this port development is a result of the surge in maritime traffic, both cargo and passenger, caused by globalisation, from which Spain, with $80 \%$ of its cargo transported by ship, has not been excluded; quite the contrary, in the last ten years this rise has exceeded the national gross domestic product, reaching double-digit figures.

ICE is to be thanked for favourably receiving the proposal by IAHR to produce an issue of Maritime Engineering dedicated to maritime engineering in Spain as a part of continuing collaboration between the two organisations.

Considerable thanks are due, in the case of Spain, to the state public ports body, ports authorities and to Cedex for their dedication in providing a series of papers of high quality and relevance. Thanks are also due to the Spanish Association of Consulting and Engineering Firms (Tecniberia/Asince) and the Association of National Construction Firms (Seopan)-both consultants and contractors-have presented several papers. Finally, thanks are due to all the authors without whom this publication would not have been possible. 